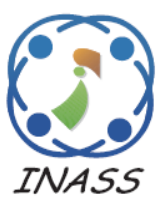

\title{
A New DC-AC Multilevel Converter with Reduced Device Count
}

\author{
Venugopal Pakala $^{1 *} \quad$ Sumathi Vijayan ${ }^{2}$ \\ 1*School of Electronics Engineering, VIT University, Vellore, Tamilnadu, India \\ ${ }^{2}$ School of Electrical Engineering, VIT University, Chennai, Tamilnadu, India \\ * Corresponding author's Email: venugopal.p@ vit.ac.in
}

\begin{abstract}
In the present paper, a novel single phase multilevel inverter using switched capacitor units is proposed. Switched capacitor unit (SCU) is used in the suggested multilevel inverter will boost the dc supply voltage at the input without using transformer by switching the capacitors in parallel and series. The proposed topology generates more number of voltage levels with less number of switches, isolated dc sources, and diodes in comparison with existing topologies. The recommended structure generates the output voltage waveform of $17-$ levels $(8$ positive, 8 negative and one zero level) with 2 capacitors, 2 diodes, 2 dc sources and 10 switches. This 17-level multilevel inverter generates the maximum output voltage and current about $80 \mathrm{~V}$ and $950 \mathrm{~mA}$ respectively, with $10 \mathrm{~V}$ and 30 $\mathrm{V}$ dc sources. Further, this topology can be extended to 49-level by including just four power switches and one more switched capacitor unit to the basic structure of proposed multilevel inverter. The feasibility and performance of the suggested multilevel converter have been assessed with simulation and experimental tests of 17-level multilevel inverter.
\end{abstract}

Keywords: Multilevel inverter, DC power sources, Switched capacitor unit, Power switches, Charging and discharging.

\section{Introduction}

Currently, multilevel inverters have gain more attention because of their high quality of output power, reduced harmonic distortion, amplitude of fundamental component is high, high efficiency, switching losses are low, and less dv/dt. These benefits said above are the inspiration for the changeover from the traditional two-level converter to multilevel converters [1]. In actuality, the multilevel inverter (MLI) intends to produce the stepwise voltage waveform at the output by integrating dc source values connected with its terminals. The output voltage levels increases by increasing the dc links count at the input. Considering the different topologies of MLI, the dc power supplies can be isolated or interconnected [2].

Three basic architectures of the multilevel DCAC converters have been exhibited: Neutral point clamped, flying capacitor and cascaded multilevel inverter $[3,4]$. The fundamental condition for producing high number of voltage levels is to utilize various dc voltage sources for example, transformers or capacitors with combination of several switching components [5]. However, these requirements make an awesome constraint for MLIs in modern applications and it is not favoured on the aspect of commercial utility. In recent literature, authors have attempted to preclude these previously mentioned constraints through presenting the recently developed MLI topologies [6]. Nevertheless, producing increased count of voltage levels at the output with least number of isolated dc power supplies and other associated components, for example, gate drivers and power switches in like manner is considered a fundamental challenge for researchers [7]. One of the practical methodologies to diminish the quantity of required dc power supplies is to utilize switched capacitor converters [8].

In the present paper, a new Multilevel Inverter using switched capacitor unit is proposed. The general advantages of the proposed topology over 
the most recent similar topologies are self-balancing with reduced number of components and the most extreme number of involved components in the current path, $N_{c}, \max$ which can impose on total conduction losses, has a noteworthy reduction in the proposed topology. Additionally, this topology generates increased number of output voltage levels compared to the topologies mentioned in the literature. Moreover, this architecture can be extended to further levels by adding the basic switched capacitor units. H-bridges are not used in this topology and will lead to less number of power electronic switches, reduced cost and complexity of the circuit. A far reaching, comparison has been done with the recently proposed structures, which can demonstrate the upsides of proposed MLI using switched capacitor structure in various perspective, such as the switch count, diodes, capacitors, number of dc sources and voltage levels at output. To examine the proposed structure, simulation has been done using MATLAB/SIMULINK and these results are verified with hardware prototype to confirm performance of the proposed structure.

This paper is organised as follows: literature review is presented in Section.2, where those already found in practice and those currently under development are addressed. In Section.3, the performance and switching patterns of proposed 17level and 49-level multilevel inverter is addressed. The analysis of power loss has been carried out in Section.4. The proposed topology is compared with existing topologies in Section.5. To validate the performance accuracy of the suggested structure, simulation and experimental results are presented in Section.6. Finally, Conclusions of the present work is addressed in Section.7.

\section{Literature review}

Multilevel converter technology started in the late 1960s, with the introduction of the multilevel stepped waveform concept with a series-connected $\mathrm{H}$-bridge, which is also known as cascaded $\mathrm{H}$ Bridge converter, [9]. This as closely followed by low-power development of a flying capacitor based multilevel inverter (FCMLI) topology the same year by Meynard and Foch. The major advantages of FCMLI are that it has redundancies for inner voltage levels; it does not require all of the switches that are ON (conducting) be in a consecutive series and phase redundancy $[10,11]$. Dozens of variants and new FCMLIs have been proposed in literature. However, these topologies require a separate voltage balancing circuit to preclude the problem of discharging $[12,13]$. This problem can be reduced by switching states repetitions. In this approach, large number of semiconductor switches is required to achieve more number of voltage levels [14]. Dargahi [15] presented a novel technique in FCMCs to balance the charge with less number of switches and gate driver circuits. However, this design generates an abnormal voltage ripples with increased levels of voltage at the output and is not possible to increase the output levels further as desired. By contrast, [16] presented a 17-level inverter by using a 3-level FCMLI and a cascaded H-bridge. This topology requires one dc voltage source and four floating capacitors which their respective voltage rating is a fraction of power supply, with 16 power switches. Meanwhile saving the number of required dc power supplies with contribution of RSS, makes a significant switching loss because of higher switching frequency of each power switch per each cycle.

Switched capacitor inverters are known as another alternative approach, in which charge balancing processes for eliminating the additional $\mathrm{dc}$ sources are not required; consequently overall cost will reduce [17]. In 1989, Marusarz [18] was developed first switched capacitor inverter. This inverter produces improved sinusoidal output waveform by boosting the dc link. Following this, Voltage equational type inverter was developed to improve the previous inverter performance by Ishimatsu et al. [19] in 1998. A programmable inverter using a ring type converter was developed by Terada et al. [20]. Utilizing a series-parallel type converter, Oota suggested a bidirectional inverter [21]. These inverters can generate square wave or improved sinusoidal wave, by controlling the switching pulses of the circuit. Be that as it may, these inverters need large number of circuit components, in light of the fact that the increased gain of these inverters is proportional to the quantity of transfer capacitors. Chang [22] recommended the multistage switched capacitor voltage multiplier DC-AC inverter to lessening the count of circuit elements. Switched capacitor voltage multiplier inverter can attain high gain by arranging the converters in series. In any case, many circuit devices are as yet vital for the switched capacitor voltage multiplier inverter, on the grounds that all the capacitors have the same voltage ratio. Kei Eguchi et. Al. [23] was developed DC-AC inverter without inductor. This makes the inverter with reduced size and weight. However, this inverter generates a square wave output voltage (2-levels) by using 17 switches and 5 capacitors.

B. Axelrod, et. al. [24] suggested a new switched capacitor multilevel inverter (SCMLI), which 
produces more number of voltage levels with less number of dc sources. Nonetheless, the operation of this inverter relies on many power semiconductor switches and additional inductors to transfer more power to the output with less number of separated dc control supplies. In contrast, the by using the switching capacitor technique in matrix inverter a novel SCMLI has developed which has noteworthy effect on limiting the total cost by diminishing the quantity of semiconductor devices and dc power supplies [25]. In this case, the switches are operating in series and parallel fashion to charge the capacitor to their nominal voltage fed straightforwardly by power supply in parallel modes, and afterward they have capacity to discharge their stored energy in series modes. This strategy, not just have more quantity of input power transfer to the output; however, likewise they can keep more number of output voltage levels. Concerning this advantage, a few enhanced topologies have been introduced in the literature by proposing the new fundamental circuits. However, these topologies have used a $\mathrm{H}-$ Bridge to change the polarity of the output voltage waveform and cascaded strategy keeping in mind the end goal to generalize the structure and achieve the higher number of the voltage levels at the output. Moreover these topologies have higher number of current paths which results more conduction losses and requires more number of switches [26-29].

The new multilevel inverter using switched capacitor unit is proposed which generates higher number of voltage levels at the output than present suggested topologies and can be formulized to extended condition. The proposed structure does not required $\mathrm{H}$-bridge cell to change the output voltage polarity and this will lead to less required power switch numbers in compare to conventional multilevel inverter structures.

\section{Proposed multilevel inverter using switched capacitor unit}

In order to generate more number of levels with reduced device count, a novel structure has been introduced, which utilizes the switched capacitor units. The basic structure of switched capacitor converter is shown in Fig.1 (a). The switched capacitor unit contains a capacitor, power diode, dc power supply and two power semiconductor switches. The capacitor will be charged to the voltage $\mathrm{V}_{\mathrm{dc}}$ when turned $\mathrm{ON}$ the switch $\mathrm{Sb}$. The capacitor will be discharged when turn ON the switch $S_{a}$. Figure 1 (b) shows the operations of charging and Fig. (c) shows the operation of discharging of capacitor.

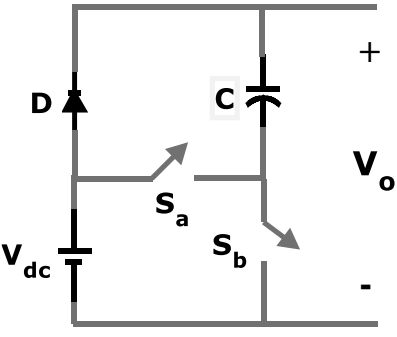

(a)

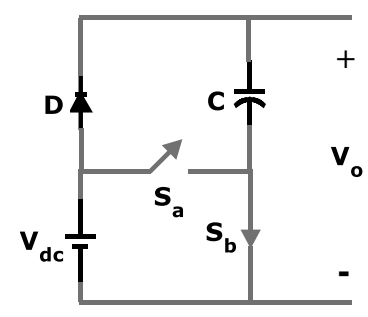

(b)

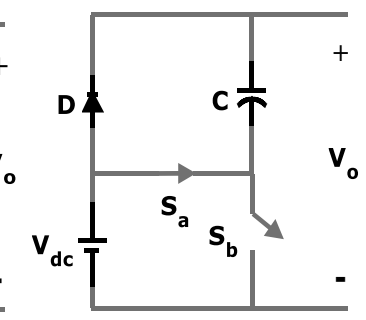

(c)
Figure.1 Basic structure of switched capacitor converter: (a) basic switched capacitor unit, (b) capacitor charging circuit, and (c) capacitor discharging circuit.

The basic architecture of proposed multilevel Inverter is shown in Figure.2, which contains 2 switched capacitor units, 6 power semiconductor switches, $2 \mathrm{dc}$ sources and $2 \mathrm{k}$ ( $\mathrm{k}$ is the half of the isolated $\mathrm{dc}$ sources) capacitors. The number of switches and power diodes required in the proposed topology can be stated as following equations;

$$
\begin{gathered}
N_{\text {Switch }}=8 k+2 \\
N_{\text {diode }}=2 k
\end{gathered}
$$

To generate maximum number of output levels 2 dc sources ae in asymmetric in nature. The mathematical expression for the dc source of second switched capacitor unit is given by,

$$
V_{d c, 2}=\left(1+2^{k}\right) V_{d c, 1}
$$

The asymmetrical proposed topology will produce maximum voltage levels at output can be expressed as following,

$$
N_{\text {level }}=1+2^{k+2}+2^{2 k+1}
$$

The seventeen levels proposed inverter is shown in Fig.3. This structure contains 10 power switches, 2 capacitors, 2 diodes and 2 isolated power supplies. The value of DC sources of first SCU and second SCU are $V_{d c}$ and $3 V_{d c}$. The switching pattern of the 17-level topology is provided in Table. 1. For example, if the value of $\mathrm{V}_{\mathrm{dc}}$ is $10 \mathrm{~V}$, and then the 
maximum voltage obtained at load is $80 \mathrm{~V}$. Each step size is $10 \mathrm{~V}$. To get $80 \mathrm{~V}$ at the output side $S_{\mathrm{B} 1}, S_{1}$, $S_{T}, S_{1}{ }_{1}, S_{B}{ }_{B}$ should be turned ON. During this period both the capacitors are in discharging mode. When switches $S_{\mathrm{B} 1}, \mathrm{~S}_{2}, \mathrm{~S}_{\mathrm{T}}, \mathrm{S}_{1}{ }_{1}, \mathrm{~S}_{\mathrm{B}} 1$ are turn $\mathrm{ON}$ simultaneously, the voltage at output will be $70 \mathrm{~V}$ with capacitor $\mathrm{C}_{1}$ charging and $\mathrm{C}_{2}$ discharging.

The proposed topology can be extended to further levels by adding SCU and switches. For instant, by adding the one SCU and two switches to the basic topology, will produce 49 level output.

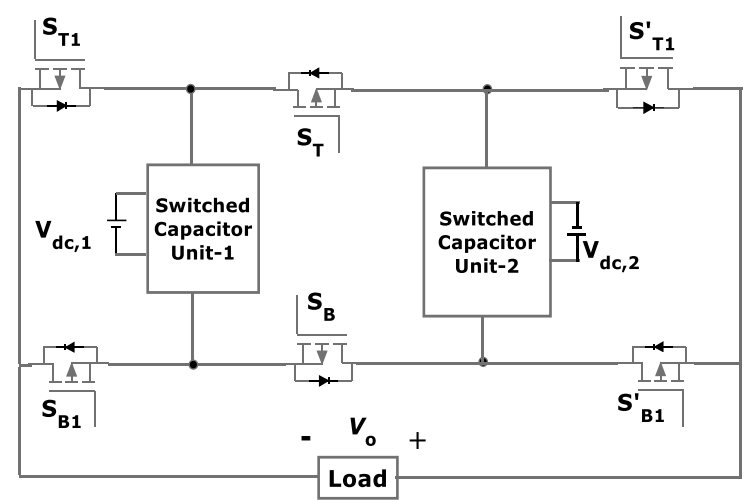

Figure.2 Basic Proposed Switched Capacitor Multilevel Inverter

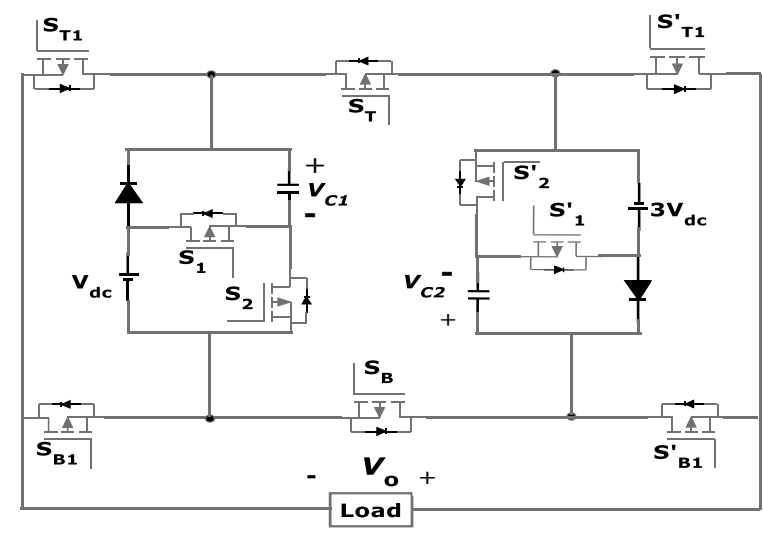

Figure.3 Proposed Seventeen Level Multilevel Inverter

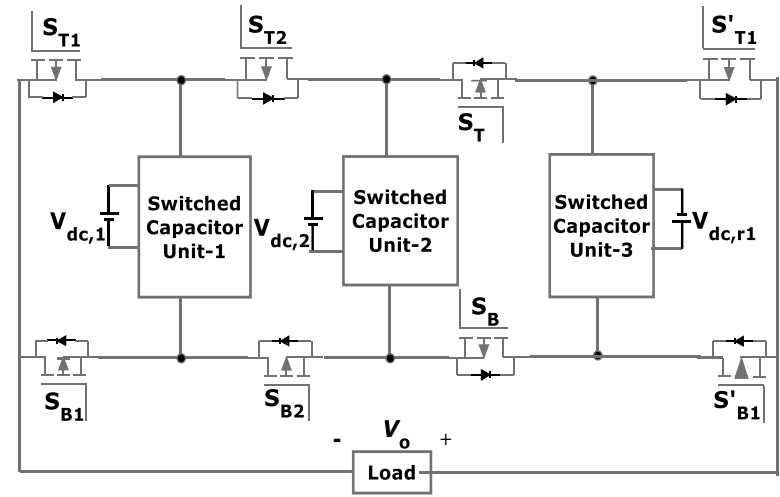

Figure.4 49-level multilevel inverter
Hence, 49 level inverter require 14 switches, 3 DC sources, 3 capacitors and 3 diodes. For example, the switches $\mathrm{S}_{\mathrm{B} 1}, \mathrm{~S}_{\mathrm{T} 2}, \mathrm{~S}_{\mathrm{T}}, \mathrm{S}_{\mathrm{T} 1}$ alongside the internal power switches of SCU-2 and SCU-3 and also internal power switch of SCU-1 must be turn ON. So as to generate 9th level of output, switches of $S_{B 1}$, $\mathrm{S}_{\mathrm{B} 2}, \mathrm{~S}_{\mathrm{T}}, \mathrm{S}_{\mathrm{T} 1}$ along with internal power switches of SCU-3 and SCU-2 and also turn ON the SCU-1 switches which are in parallel. The switching sequence is given in the Table. 2. To create higher number of voltage levels at the output side with regard to further levels, the value of additional dc power sources of individually SC unit can be implemented by the given expressions:

$$
\begin{aligned}
& V_{d c, j}=2\left(V_{d c, j-1}+V_{d c, r(j-1)}\right)+1 \\
& V_{d c, r j}=2\left(V_{d c, j}+V_{d c, r(j-1)}\right)+1
\end{aligned}
$$

Table 1. Switching Sequence of Seventeen Level

\begin{tabular}{|c|c|c|}
\hline S. No & ON Switches & Output Voltage Vo \\
\hline 1 & $\mathrm{~S}_{\mathrm{B} 1}, \mathrm{~S}_{1}, \mathrm{~S}_{\mathrm{T}}, \mathrm{S}^{\prime}{ }_{1}, \mathrm{~S}_{\mathrm{B} 1}$ & $4 V_{\mathrm{dc}}+\mathrm{v}_{\mathrm{c} 1}+\mathrm{v}_{\mathrm{c} 2}$ \\
\hline 2 & $\mathrm{~S}_{\mathrm{B} 1}, \mathrm{~S}_{2}, \mathrm{~S}_{\mathrm{T}}, \mathrm{S}^{\prime}{ }_{1}, \mathrm{~S}_{\mathrm{B} 1}$ & $4 V_{d c}+v_{c 2}$ \\
\hline 3 & $\mathrm{~S}_{\mathrm{T} 1}, \mathrm{~S}_{2}, \mathrm{~S}_{\mathrm{T}}, \mathrm{S}^{\prime}{ }_{1}, \mathrm{~S}^{\prime}{ }_{\mathrm{B} 1}$ & $3 \mathrm{~V}_{\mathrm{dc}}+\mathrm{v}_{\mathrm{c} 2}$ \\
\hline 4 & $\mathrm{~S}_{\mathrm{B} 1}, \mathrm{~S}_{1}, \mathrm{~S}_{\mathrm{T}}, \mathrm{S}_{2}^{\prime}, \mathrm{S}_{\mathrm{B} 1}$ & $4 V_{d c}+v_{c 2}$ \\
\hline 5 & $\mathrm{~S}_{\mathrm{B} 1}, \mathrm{~S}_{2}, \mathrm{~S}_{\mathrm{T}}, \mathrm{S}_{2}{ }_{2}, \mathrm{~S}_{\mathrm{B} 1}$ & $4 V_{\mathrm{dc}}$ \\
\hline 6 & $\mathrm{~S}_{\mathrm{T} 1}, \mathrm{~S}_{2}, \mathrm{~S}_{\mathrm{T}}, \mathrm{S}_{2}, \mathrm{~S}_{\mathrm{B} 1}$ & $3 \mathrm{~V}_{\mathrm{dc}}$ \\
\hline 7 & $\mathrm{~S}_{\mathrm{B} 1}, \mathrm{~S}_{1}, \mathrm{~S}_{\mathrm{T}}, \mathrm{S}_{2}{ }_{2}, \mathrm{~S}_{\mathrm{T} 1}^{\prime}$ & $\mathrm{V}_{\mathrm{dc}}+\mathrm{V}_{\mathrm{c} 1}$ \\
\hline 8 & $\mathrm{~S}_{\mathrm{B} 1}, \mathrm{~S}_{2}, \mathrm{~S}_{\mathrm{T}}, \mathrm{S}_{2}{ }_{2}, \mathrm{~S}_{\mathrm{T} 1}^{\prime}$ & $\mathrm{V}_{\mathrm{dc}}$ \\
\hline 9 & $\mathrm{~S}_{\mathrm{B} 1}, \mathrm{~S}_{2}, \mathrm{~S}_{\mathrm{B}}, \mathrm{S}_{2}{ }_{2}, \mathrm{~S}_{\mathrm{B} 1}$ & 0 \\
\hline 10 & $\mathrm{~S}_{\mathrm{T} 1}, \mathrm{~S}_{2}, \mathrm{~S}_{\mathrm{B}}, \mathrm{S}_{2}{ }_{2}, \mathrm{~S}_{\mathrm{B} 1}^{\prime}$ & $-\mathrm{V}_{\mathrm{dc}}$ \\
\hline 11 & $\mathrm{~S}_{\mathrm{T} 1}, \mathrm{~S}_{1}, \mathrm{~S}_{\mathrm{B}}, \mathrm{S}^{\prime}{ }_{2}, \mathrm{~S}_{\mathrm{B} 1}$ & $-\mathrm{V}_{\mathrm{dc}}-\mathrm{V}_{\mathrm{c} 1}$ \\
\hline 12 & $\mathrm{~S}_{\mathrm{B} 1}, \mathrm{~S}_{2}, \mathrm{~S}_{\mathrm{B}}, \mathrm{S}_{2}{ }_{2}, \mathrm{~S}^{\prime}{ }_{\mathrm{B}} 1$ & $-3 V_{d c}$ \\
\hline 13 & $\mathrm{~S}_{\mathrm{T} 1}, \mathrm{~S}_{2}, \mathrm{~S}_{\mathrm{B}}, \mathrm{S}_{2}{ }_{2}, \mathrm{~S}_{\mathrm{B} 1}$ & $-4 V_{d c}$ \\
\hline 14 & $\mathrm{~S}_{\mathrm{T} 1}, \mathrm{~S}_{1}, \mathrm{~S}_{\mathrm{B}}, \mathrm{S}_{2}{ }_{2}, \mathrm{~S}_{\mathrm{B} 1}$ & $-4 V_{d c}-V_{c 2}$ \\
\hline 15 & $\mathrm{~S}_{\mathrm{B} 1}, \mathrm{~S}_{2}, \mathrm{~S}_{\mathrm{B}}, \mathrm{S}^{\prime}{ }_{1,} \mathrm{~S}^{\prime}{ }_{\mathrm{B} 1}$ & $-3 V_{d c}-V_{c 2}$ \\
\hline 16 & $\mathrm{~S}_{\mathrm{T} 1}, \mathrm{~S}_{2}, \mathrm{~S}_{\mathrm{B}}, \mathrm{S}_{1}{ }_{1}, \mathrm{~S}_{\mathrm{B} 1}$ & $-4 V_{d c}-V_{c 2}$ \\
\hline 17 & $\mathrm{~S}_{\mathrm{T} 1}, \mathrm{~S}_{1}, \mathrm{~S}_{\mathrm{B}}, \mathrm{S}_{1}{ }_{1}, \mathrm{~S}_{\mathrm{B} 1}$ & $-4 V_{d c}-V_{c 1}-V_{c 2}$ \\
\hline
\end{tabular}
Multilevel Inverter

Table 2. Different states of switching of 49-Level Multilevel Inverter

\begin{tabular}{|c|l|l|}
\hline S. No & \multicolumn{1}{|c|}{ ON Switches } & \multicolumn{1}{c|}{$\begin{array}{c}\text { Output } \\
\text { Voltage, Vo }\end{array}$} \\
\hline $\mathbf{1}$ & $\mathrm{S}_{\mathrm{B} 1}, \mathrm{~S}_{\mathrm{T} 2}, \mathrm{~S}_{\mathrm{T}}, \mathrm{S}^{\prime}{ }_{\mathrm{T} 1}$ & 1,2 \\
\hline $\mathbf{2}$ & $\mathrm{S}_{\mathrm{T} 1}, \mathrm{~S}_{\mathrm{T} 2}, \mathrm{~S}_{\mathrm{T}}, \mathrm{S}^{\prime}{ }_{\mathrm{B} 1}$ & 3,6 \\
\hline $\mathbf{3}$ & $\mathrm{S}_{\mathrm{B} 1}, \mathrm{~S}_{\mathrm{T} 2}, \mathrm{~S}_{\mathrm{T}}, \mathrm{S}^{\prime}{ }_{\mathrm{B} 1}$ & $4,5,7,8$ \\
\hline $\mathbf{4}$ & $\mathrm{S}_{\mathrm{B} 1}, \mathrm{~S}_{\mathrm{B} 2}, \mathrm{~S}_{\mathrm{T}}, \mathrm{S}^{\prime}{ }_{\mathrm{T} 1}$ & 9,18 \\
\hline $\mathbf{5}$ & $\mathrm{S}_{\mathrm{T} 1}, \mathrm{~S}_{\mathrm{B} 2}, \mathrm{~S}_{\mathrm{T}}, \mathrm{S}^{\prime}{ }_{\mathrm{B} 1}$ & $10,11,13,14,19$, \\
& & $20,22,23$ \\
\hline $\mathbf{6}$ & $\mathrm{S}_{\mathrm{B} 1, \mathrm{~S}_{\mathrm{B} 2}, \mathrm{~S}_{\mathrm{T}}, \mathrm{S}^{\prime}{ }_{\mathrm{B} 1}}$ & 12.15 .21 .24 \\
\hline $\mathbf{7}$ & $\mathrm{S}_{\mathrm{T} 1, \mathrm{~S}_{\mathrm{B} 2}, \mathrm{~S}_{\mathrm{T}}, \mathrm{S}^{\prime}{ }_{\mathrm{T} 1}}$ & 16,17 \\
\hline
\end{tabular}




\section{Analysis of power loss for 17-level suggested structure}

The total power losses of this inverter includes: Conduction losses Pc, Switching losses Psw, Losses due to ripples in the capacitor. Fundamental frequency of switching technique has been used to calculate the above losses.

\subsection{Losses due to switching}

Switching losses take place for the period of ON and OFF switching states. A linear approximation between voltage and current of switches has been assumed in the switching period. By using this assumption, switching power losses can be calculated for the ith switch as follows:

$$
\begin{aligned}
P_{s w, o n, i} & =f \int_{0}^{t_{\text {on }}} v_{s w, i}(t) i(t) d t \\
& =f \int_{0}^{t_{\text {on }}}\left(\frac{V s w, i}{t_{\text {on }}} t\right)\left(-\frac{I_{i}}{t_{\text {on }}}\left(t-t_{\text {on }}\right)\right) \mathrm{dt} \\
& =\frac{1}{6} f V_{\text {sw,i }} I_{i} t_{\text {on }}
\end{aligned}
$$

Where $V_{s w, i}$ is the OFF state voltage of $i^{\text {th }}$ switch. I and I' are the $i^{\text {th }}$ switch current after turn $\mathrm{ON}$ and before turn OFF respectively. The fundamental switching frequency is denoted by $f . P_{s w, o n, i}$ and $P_{s w, o f f, i}$ are the switching power loss during ON and OFF states.

$$
\begin{aligned}
P_{s w, o f f, i} & =f \int_{0}^{t_{\text {off }}} v_{s w, i}(t) i(t) d t \\
& =f \int_{0}^{t_{\text {off }}}\left(\frac{V_{s w, i}}{t_{o n}} t\right)\left(-\frac{I_{i}^{\prime}}{t_{o f f}}\left(t-t_{o f f}\right)\right) \mathrm{dt} \\
& =\frac{1}{6} f V_{s w, i} I_{i} t_{o f f}
\end{aligned}
$$

The total switching power losses is given by

$$
P_{s w}=P_{s w, o n . i}+P_{s w, o f f, i}
$$

\subsection{Losses due to conduction}

Operation modes of capacitor charging and discharging are demonstrated in Fig.5 (a) and (b). In these figures, Ron, $\mathrm{R}_{\mathrm{D}}, \mathrm{r}_{\mathrm{ER}}, \mathrm{R}_{\mathrm{L}}$ and $\mathrm{V}_{\mathrm{F}}$ are switch internal ON-state resistance, diode internal resistance, capacitor's series equivalent resistance (ESR), resistance of the load and forward voltage drop of each incurred diodes, respectively.

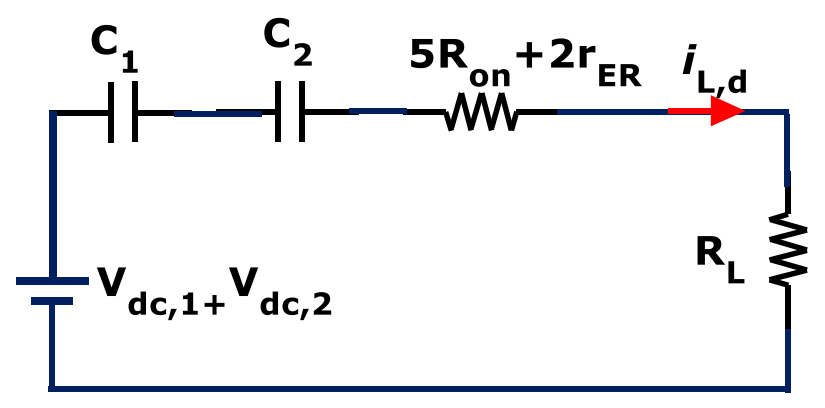

(a)

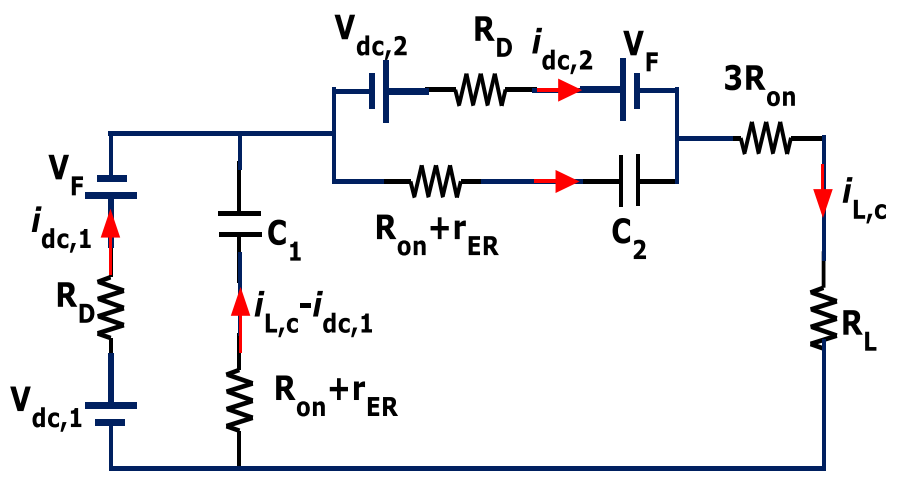

(b)

Figure.5 (a) Capacitor Discharging Mode Equivalent Circuit. (b) Capacitor charging Mode Equivalent Circuit

The value of load current can be calculated from Fig. 5 (a),

$$
i_{L, d}=\frac{4 V d c, 1+v_{c 1}+v_{c 2}}{5 R_{o n}+2 r_{E R}+R_{L}}
$$

Conduction losses during discharging period, $\mathrm{P}_{\mathrm{c}, \mathrm{d}}$ and Conduction losses during charging period, $\mathrm{P}_{\mathrm{c}, \mathrm{c}}$ can be determined as follows,

$$
\begin{gathered}
P_{c, d}=\left(5 R_{o n}+2 r_{E R}\right) i^{2}{ }_{L, d} \\
P_{c, c}=3 R_{o n} i^{2}{ }_{L, c}+R_{D}\left(i^{2} d c, 1+i^{2} d c, 2\right) \\
+\left(R_{o n}+r_{E R}\right)\left[\left(i_{L, c}-i_{d c, 1}\right)^{2}\right. \\
\left.+\left(i_{L, c}-i_{d c, 2}\right)^{2}\right]
\end{gathered}
$$


Therefore, the total conduction losses is given by

$$
P_{c}=P_{c, d}+P_{c, c}+3 R_{o n} I_{r m s, L}^{2}
$$

Where $\mathrm{I}_{\mathrm{rms}, \mathrm{L}}$ is the load current rms value.

\subsection{Losses due to ripple}

During charging operation of the capacitors, the difference between the respected input voltage and the voltage of capacitors $\left(\mathrm{V}_{\mathrm{ci}}(i=1,2)\right)$ [25] causes arising of ripple losses. Thus, the capacitor voltage ripple $\Delta V_{c i}$ is given by

$$
\Delta V_{C i}=\frac{1}{C_{i}} \int_{t^{\prime}}^{t} i_{C i}(t) d t
$$

Where, $i_{C i}(t)$ is the current of capacitor and the time interval for discharging modes is $\left[\mathrm{t}^{\prime}-\mathrm{t}\right]$, which can be obtained by regarding to Table 1 . Thus, the total value of ripple loss, for one full cycle of output waveform is equal to

$$
P_{r i p}=\frac{f}{2} \sum_{i=1}^{2} C_{i} \Delta V^{2}{ }_{c i}
$$

The total loss of the suggested topology is the sum of switching, conduction and ripples losses and is expressed as follows,

$$
P_{l o s s e s}=P_{s w}+P_{c}+P_{r i p}
$$

Overall efficiency can be calculated as,

$$
\eta=\frac{P_{\text {out }}}{P_{\text {out }}+P_{\text {losses }}}
$$

\section{Comparison of proposed structure with some existing structures}

The proposed multilevel inverter using switched capacitor unit is compared with recent similar multilevel inverter topologies [14], [15] and [16]. Table.3 provides the comparison of various parameters such as number of voltage levels at output, number of power switches and dc sources, power diodes and capacitors required for the circuit. Clearly, as for the measures of extent of count of levels of the voltage at output over the number of required devices, the recommended structure requires minimum number of devices in contrast with their relevant architectures. For example, 16, 18 and 20 semiconductor switching components to produce 17, 19, 7 levels of voltage at output, respectively, while proposed architecture requires just 10 control switches for its 17-level topology. In addition to that, recommended structure in [14],[15] and [16] need 16, 18 and 20 and 4,4, and 4 power diodes and capacitors respectively, to produce 17 , 19, 7 levels of voltage at output, respectively, while recommended architecture needs just 12 diodes and 2 capacitors for its 17 -level topology. Table 4 shows the comparison between recommended structure and existing topologies based on number of switches and capacitors used. It is clear that, the topology presented in this work requires less number of switches and capacitors. Table.5 provides the comparison of efficiency of the present topology with existing topologies. It is obvious that, proposed structure has better efficiency than [23] and almost equal with [30].

Table 3. Comparison of 17- level inverter with topologies [14], [15], and [16]

\begin{tabular}{|c|c|c|c|c|}
\hline $\begin{array}{l}\text { Key } \\
\text { Parameters }\end{array}$ & {$[14]$} & {$[15]$} & {$[16]$} & $\begin{array}{c}\text { Proposed } \\
\text { SCMLI }\end{array}$ \\
\hline$N_{\text {level }}$ & 7 & 19 & 17 & 17 \\
\hline$N_{\text {IGBT }}$ & 20 & 18 & 16 & 10 \\
\hline$N_{\text {diode }}$ & 20 & 18 & 16 & 12 \\
\hline$N_{\text {cap }}$ & 4 & 4 & 4 & 2 \\
\hline$N_{\text {source }}$ & 2 & 2 & 1 & \\
\hline$N_{c, \text { max }}$ & 10 & 9 & 8 & 5 \\
\hline $\begin{array}{l}\text { Charge } \\
\text { balance } \\
\text { requirement }\end{array}$ & YES & YES & YES & NO \\
\hline
\end{tabular}

Table 4. Comparison based on number of switches and capacitors

\begin{tabular}{|l|c|c|}
\hline Type of Inverter & $\begin{array}{c}\text { Number of } \\
\text { Switches }\end{array}$ & $\begin{array}{c}\text { Number of } \\
\text { Capacitors }\end{array}$ \\
\hline $\begin{array}{l}\text { Proposed SCMLI } \\
\text { (17-level) }\end{array}$ & 10 & 2 \\
\hline $\begin{array}{l}\text { Inductor-Less DC-AC } \\
\text { Inverter[23] }\end{array}$ & 17 & 5 \\
\hline $\begin{array}{l}\text { Series-parallel type } \\
\text { inverter [21] }\end{array}$ & 38 & 12 \\
\hline Ring type inverter [20] & 48 & 12 \\
\hline Multistage SCVM [22] & 26 & 8 \\
\hline $\begin{array}{l}\text { Voltage equational type } \\
\text { inverter [19] }\end{array}$ & 29 & 12 \\
\hline
\end{tabular}

Table 5. Comparison based on the efficiency

\begin{tabular}{|c|c|c|c|}
\hline Key Parameter & {$[\mathbf{2 3}]$} & {$[\mathbf{3 0}]$} & $\begin{array}{c}\text { Proposed } \\
\text { SCMLI }\end{array}$ \\
\hline Efficiency & $80 \%$ & $90 \%$ & $90 \%$ \\
\hline
\end{tabular}




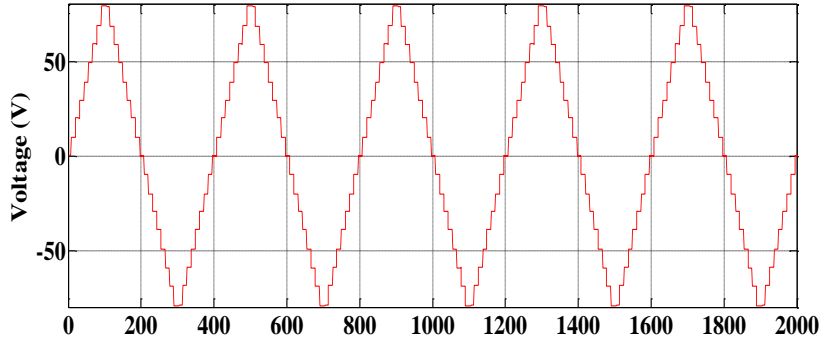

(a)

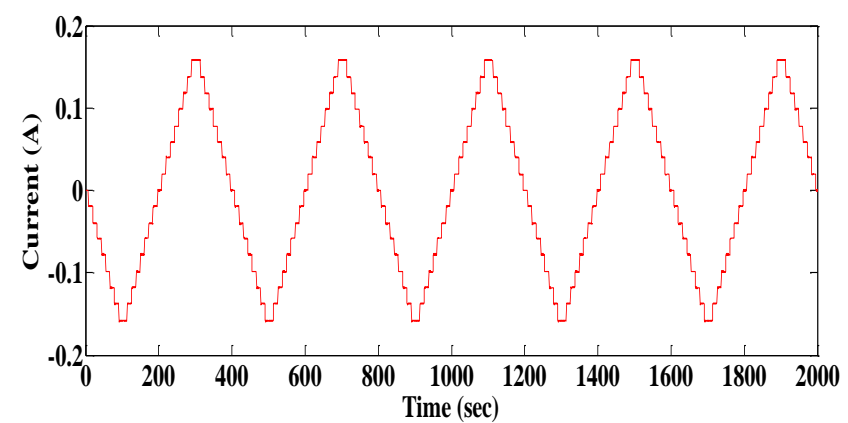

(b)

Figure.6 Simulation waveforms of 17-level multilevel inverter (a) output voltage wave form (b) Current waveform

\section{Simulation and experimental results}

To analyse the performance of recommended switching capacitor based multilevel inverter, the simulation and experimental results of 17-level inverter are presented. MATLAB/Simulink has been used for simulation. In addition to that, the hardware prototype of seventeen-level inverter with $80 \mathrm{~V}$ has been developed. The FPGA spartan-3e has been used to produce the gating pulses. For the present structure fundamental switching frequency method is used. The MOSFETs used are IRF-840, $500 \mathrm{~V}, 8 \mathrm{~A}$ and Ron is $0.85 \Omega$ and Power diodes used are FR107, $700 \mathrm{~V}$ and $50 \Omega$. Capacitors have been used with $4700 \mu \mathrm{F}$ and $50 \mathrm{~V}$. The prototype has been tested on R-L load with the magnitude of 0.5 $\mathrm{mH}$ and $500 \Omega$ for all the studies.

In this topology, the values of dc sources are unequal and are $10 \mathrm{~V}$ and $30 \mathrm{~V}$. According to this present topology produces the maximum voltage at the output will be $80 \mathrm{~V}$. R-L load have been used for both simulation and experimental tests. The simulation results of proposed multilevel inverter which produces 17-level have shown in Fig.6 (a) and (b). It is observed that the output voltage is 80 $\mathrm{V}$ and current is $950 \mathrm{~mA}$.

Hardware setup is shown in Fig.7.The experimental results of proposed architecture which produces 17 levels ( 8 positive levels, 8 negative levels and 1 zero level) having maximum voltage of almost 78V and current of $929 \mathrm{~mA}$ is shown in Fig.8.

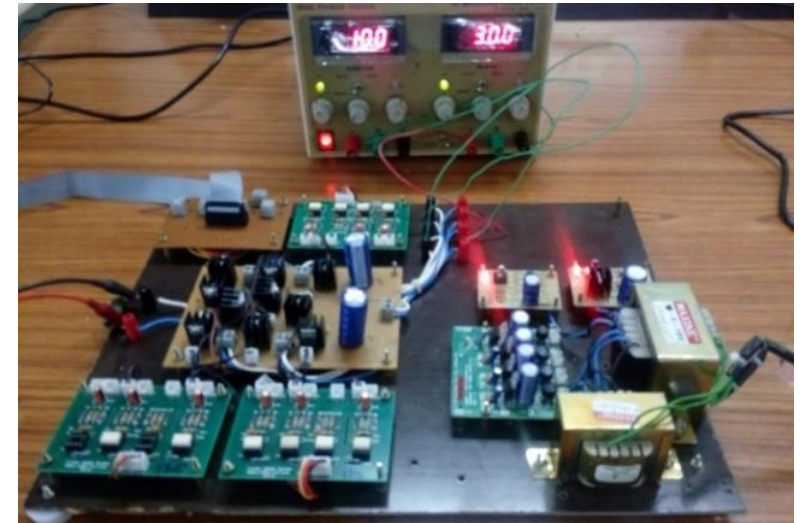

Figure.7 Hardware Setup of 17-Level Proposed Topology

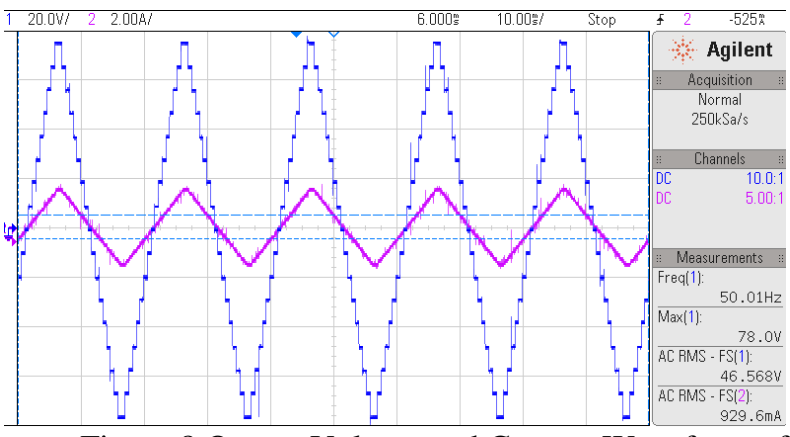

Figure.8 Output Voltage and Current Waveform of Proposed Seventeen-Level MLI

It is clear that the experimental results are good agreement with simulation results. Figure 9 shows that the blocking voltage waveforms of various switches $S_{T}, S_{T 1}, S^{\prime}{ }_{T 1}, S_{1}, S_{1}$ from experimental setup. We can notice that the extreme value of blocking voltage across the power switches is less than the maximum withstand voltage of $80 \mathrm{~V}$. The output power of the suggested structure is $65.21 \mathrm{~W}$ and the losses are $7.05 \mathrm{~W}$. Therefore, efficiency of the proposed topology is around $90 \%$.

\section{Conclusions}

In this paper, a novel multilevel inverter topology using switched capacitor unit has been proposed to produce higher number of levels at the output with minimum number of components. The basic proposed structure produces the output voltage waveform of 17-levels with 2 capacitors, 2 diodes, 2 dc sources and 10 switches. The basic topology can be extended to any number of levels at the output, for example, by adding one switched capacitor unit and 2 more switches to the 17- level multilevel inverter, 49-levels at output will be obtained. The proposed topology has been compared with several existing topologies in the literature from the various points of observation. Based on these comparisons, the proposed structure requires less number of 
power switches, dc sources, capacitors and diodes. Consequently the size and cost of the proposed structure will be reduced in comparison with the conventional similar topologies. At last, the viability and performance of recommended 17-level switched capacitor multilevel inverter have been confirmed through simulation and experimental results.

Implementation of switching capacitor multilevel inverter based active power filter is left for future study.

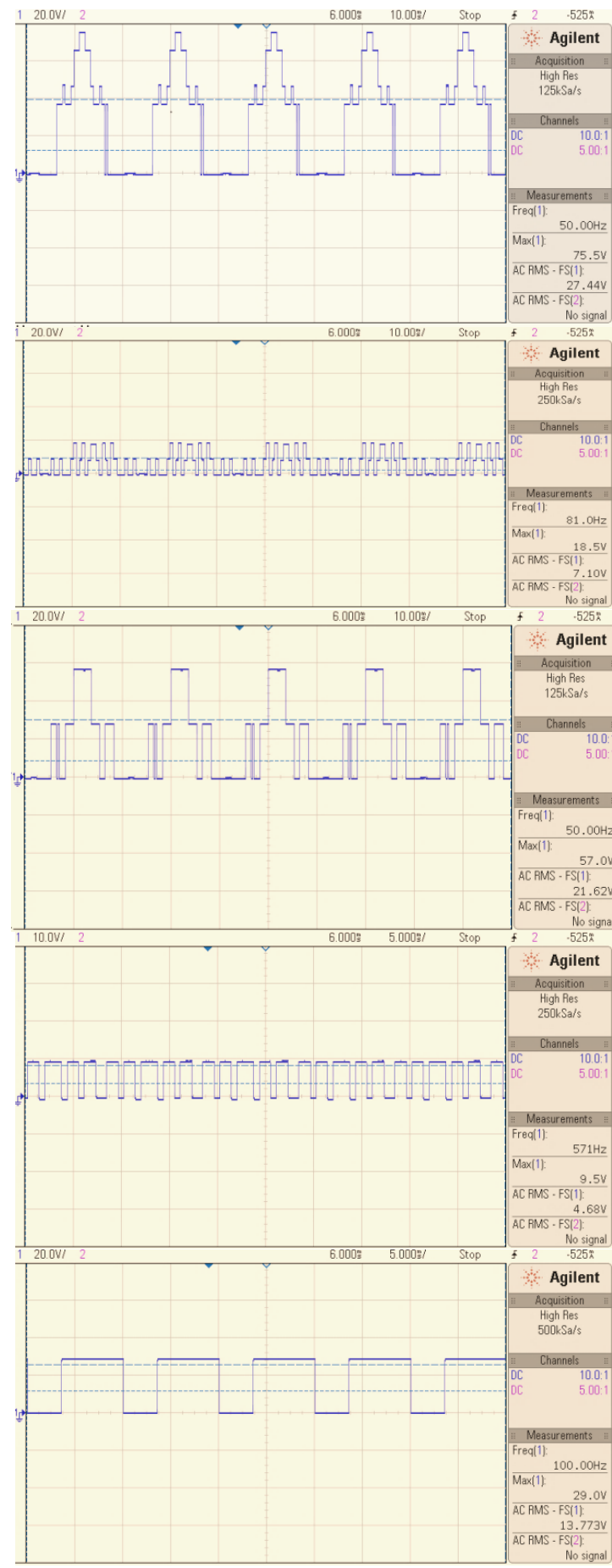

Figure.9 Blocking Voltages of Switches $\mathrm{S}_{\mathrm{T}}, \mathrm{S}_{\mathrm{T} 1}, \mathrm{~S}_{\mathrm{T} 1}, \mathrm{~S}_{1}$, $\mathrm{S}{ }_{1}$

\section{References}

[1] J. Chavarria, D. Biel, F. Guinjoan, C. Meza, and J. J. Negroni, "Energy balance control of PV cascaded multilevel grid-connected inverters under level-shifted and phase-shifted PWMs", IEEE Transactions on Industrial Electronics, Vol. 60, No. 1, pp. 98-111, 2013.

[2] A. L. Batschauer, S. A. Mussa, and M. L. Heldwein, "Three-phase hybrid multilevel inverter based on half-bridge modules", IEEE Transactions on Industrial Electronics, Vol. 59, No. 2, pp. 668-678, 2012.

[3] S. Kouro, M. Malinowski, K. Gopakumar, J. Pou, L. Franquelo, B. Wu, J. Rodriguez, M. Perez, and J. Leon, "Recent advances and industrial applications of multilevel converters", IEEE Transactions on Industrial Electronics, Vol. 57, No. 8, pp. 2553-2580, 2010.

[4] E. Babaei, S. Alilu, and S. Laali, "A new general topology for cascaded multilevel inverters with reduced number of components based on developed H-bridge", IEEE Transactions on Industrial Electronics, Vol. 61, No. 8, pp. 39323939, 2014.

[5] M. R. Banaei and E. Salary, "New multilevel inverter with reduction of switches and gate driver", Energy Conversion Management, Vol. 52, No. 2, pp. 1129-1136, 2011.

[6] A. Ajami, M. R. J. Oskuee, A. Mokhberdoran, and H. Shokri, "Selective harmonic elimination method for wide range of modulation indexes in multilevel inverters using ICA", Journal of Central South University, Vol. 21, No. 4, pp. 1329-1338, 2014.

[7] R. Stala, "A natural DC-link voltage balancing of diode-clamped inverters in parallel systems", IEEE Transactions on Industrial Electronics, Vol. 60, No. 11, pp. 5008-5018, 2013.

[8] K.K. Gupta, A. Ranjan, P. Bhatnagar, L.K. Sahu, and S. Jain, "Multilevel inverter topologies with reduced device count: A review", IEEE Transactions on Power Electronics, Vol.31, No.1, pp.135-151, 2015.

[9] S. Kouro, , M. Malinowski, , K. Gopakumar, J. Pou, L. G. Franquelo, Bin Wu, Jose Rodriguez, Marcelo A. Pérez, and Jose I. Leon, "Recent Advances and Industrial Applications of Multilevel Converters", IEEE Transactions on Industrial Electronics, Vol. 57, No. 8, pp.25532580, 2010.

[10] S.Fazel, S. Bernet, D. Krug, and K. Jalili, "Design and comparison of 4-kv neutral-pointclamped, flying-capacitor, and series-connected H-bridge multilevel converters", IEEE 
Transactions on Industrial Electronics, Vol. 43, No. 4, pp. 1032-1040, 2007.

[11] K. D. Papastergiou, P. W. Wheeler, and J. C. Clare, "Comparison of losses in multilevel converters for aerospace applications", In: Proc. IEEE Power Electron. Specialist Conf., pp. 4307-4312, 2008.

[12] B. P. McGrath and D. G. Holmes, "Analytical modelling of voltage balance dynamics for a flying capacitor multilevel converter", IEEE Transactions on Power Electronics, Vol. 23, No. 2, pp. 543-550, 2008.

[13] M. Khazraei, H. Sepahvand, K. A. Corzine, and M. Ferdowsi, "Active capacitor voltage balancing in single-phase flying-capacitor multilevel power converters", IEEE Transactions on Industrial Electronics, Vol. 59, No. 2, pp. 769-778, 2012.

[14] V. Dargahi, A. K. Sadigh, M. Abarzadeh, S. Eskandari, and K. Corzine, "A new family of modular multilevel converter based on modified flying capacitor multi cell converters", IEEE Transactions on Power Electronics, Vol. 30, No. 1, pp. 138-147, 2015.

[15] V. Dargahi, A. K. Sadigh, M. Abarzadeh, M. R. A. Pahlavani, and A. Shoulaie, "Flying capacitor reduction in an improved double flying capacitor multi-cell converter controlled by a modified modulation method", IEEE Transactions on Power Electronics, Vol. 27, No. 9, pp. 3875-3887, 2012.

[16] P. Roshankumar, R. S. Kaarthic, K. Gupakumar, J. I. Leon, and L. G. Franquelo," A seventeenlevel inverter formed by cascading flying capacitor and floating capacitor H-bridge", IEEE Transactions on Power Electronics, Vol. 30, No. 7, pp. 3471-3478, 2015.

[17] M. S.W. Chan and K. T. Chau, "A new switched-capacitor boost multilevel inverter using partial charging", IEEE Trans. Circuits Syst. II, Exp. Briefs, Vol. 54, No. 12, pp. 11451149, 2007.

[18] R. Marusarz, "A switched capacitor, inductor less DC to AC voltage step-up power converter", In: Proc. of the 20th Annual Power Electronics Specialists Conf., pp.99-103, 1989.

[19] K. Ishimatsu, I. Oota, and F. Ueno. "A DC-AC converter using a voltage equational type switched-capacitor transformer", In: Proc. of the Thirteenth Annual Applied Power Electronics Conf. and Exposition, APEC'98, Vol. 2, pp. 603-606, 1998.

[20] S. Terada, I. Oota, K. Eguchi, and F. Ueno. "A ring type switched-capacitor (SC) programmable converter with DC or AC input/
DC or AC output", In: Proc. of the 47th IEEE International Midwest Symposium on Circuits and Systems., pp. I-29 - I-32, 2004.

[21] M. Oota, S. Terada, K. Eguchi, and I. Oota. "Development of switched-capacitor bidirectional DC-AC converter for inductive and capacitive loads", In: Proc. of IEEE International Symposium on Industrial Electronics., pp. 1618-1623, 2009.

[22] Y. H. Chang, "Modelling and analysis of multistage switched-capacitor-voltagemultiplier boost DC-AC inverter", In: Proc. of IEEE 9th International Conf. on Power Electronics and Drive Systems, PEDS 2011, pp. 523- 526, 2011.

[23] K. Eguchi, K. Abe and W. Do, "Synthesis and Analysis of a Simple Inductor-Less DC-AC Inverter", In: Proc. of 6th International Workshop on Computer Science and Engineering, pp.315-319, 2016.

[24] B. Axelrod, Y. Berkovich, and A. Ioinovici, "A cascade boost switched capacitor-converter two-level inverter with an optimized multilevel output waveform", IEEE Transactions on Circuits Syst. I, Vol. 52, No. 12, pp. 2763-2770, 2005.

[25] Y. Hinago and H. Koizumi, "A switchedcapacitor inverter using series/ parallel conversion with inductive load", IEEE Transactions on Industrial Electronics, Vol. 59, No. 2, pp. 878-887, 2012.

[26] J. Liu, K. W. E, Cheng, and Y. Ye, "A cascaded multilevel inverter based on switchedcapacitor for high-frequency ac power distribution system", IEEE Transactions on Power Electronics, Vol. 22, No. 8, pp 42194230, 2014.

[27] E. Babaei and F. Sedaghati, "Series-parallel switched-capacitor based multilevel inverter", In: Proc. Int. Conf. Electr. Mach. Syst., pp 1-5, 2011.

[28] Y. Ye, K. Cheng, J. Liu, and K. Ding, “A stepup switched-capacitor multilevel inverter with self-voltage balancing", IEEE Transactions on Industrial Electronics, Vol. 61, No. 12, pp. 6672-6680, 2014.

[29] E. Babaei and S. S. Gowgani, "Hybrid multilevel inverter using switched capacitor units", IEEE Transactions on Industrial Electronics, Vol. 61, No. 9, pp. 4614-4621, 2014.

[30] K. Eguchi, K. Abe, W. Do and H. Sasaki, "Design of Inductor-Less DC-AC Inverter Using A step-Down Fibonacci Sequence 
Generator", ICICI Express Letters, Vol.10.

No.8, pp.1951-1956, 2016. 